Canadian

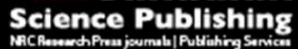

Canadian Journal of Physiology and Pharmacology Revue canadienne de physiologie et pharmacologie

\title{
Effects of fisetin on hyperhomocysteinemia- induced experimental endothelial dysfunction and vascular dementia
}

\begin{tabular}{|r|l|}
\hline Journal: & Canadian Journal of Physiology and Pharmacology \\
\hline Manuscript ID & cjpp-2016-0147.R1 \\
\hline Manuscript Type: & Article \\
\hline Date Submitted by the Author: & $26-$ May-2016 \\
\hline Complete List of Authors: & $\begin{array}{l}\text { Hemanth Kumar, Boyina; Anurag Group of Institutions, Pharmacology; } \\
\text { Jawaharlal Nehru Technological University, Pharmaceutical sciences, } \\
\text { Research and Development cell } \\
\text { Arun Reddy, Ravula; Anurag Group of Institutions, Pharmacology; Rowan } \\
\text { university 1603 west stiles street Philadelphia 19121 USA, Graduate } \\
\text { student Biomedical sciences } \\
\text { Mahesh Kumar, Jerald; Centre for Cellular and Molecular Biology CSIR, } \\
\text { Animal House Facility } \\
\text { Dinesh Kumar, B.; National Institute of Nutrition, Food \& Drug Toxicology } \\
\text { Research Centre (FDTRC) } \\
\text { Diwan, Prakash; Anurag group of institutions(Formerly Lalitha College of } \\
\text { pharmacy), Pharmacology ; Maratha mandal Group of } \\
\text { Institutions, Pharmacology }\end{array}$ \\
\hline Keyword: & $\begin{array}{l}\text { Acetylcholinesterase, Morris water maze, L-NAME, Necrotic foci, L- } \\
\text { methionine }\end{array}$ \\
\hline
\end{tabular}




\section{Effects of fisetin on hyperhomocysteinemia- induced experimental endothelial dysfunction and vascular dementia}

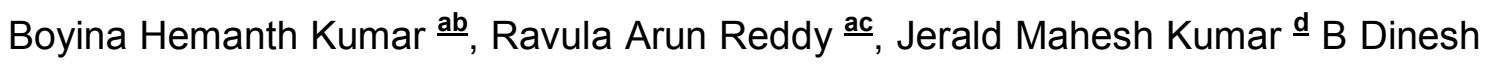

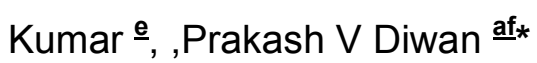

a Department of Pharmacology, Anurag Group of Institutions (Formerly Lalitha College of Pharmacy), Hyderabad, Telangana, India.

b Pharmaceutical sciences, Research and Development cell, Jawaharlal Nehru Technological University, Hyderabad, Telangana, India.

c Graduate school of Biomedical sciences , Rowan University ,Stratford, 08084 , NJ, USA.

d Animal House Facility, CSIR-Centre for Cellular and Molecular Biology (CCMB), Hyderabad, 500 007, India

e National Institute of Nutrition (ICMR), Food \& Drug Toxicology Research Centre (FDTRC) , Hyderabad, Telangana, 500007, India.

${ }^{f}$ Maratha Mandal Group of Institutions, Belagavi-590010, Karnataka, India.

${ }^{*}$ Address for Correspondence:

\section{Dr. Prakash V Diwan, PhD., FRSC (London), FIPS}

Director and Dean, School of Pharmacy,

Anurag Group of Institutions (Autonomous),

(Formerly Lalitha College of Pharmacy), Ghatkesar-500088,

Hyderabad, Telangana. India.

Email: diwanpv@gmail.com 


\section{Abstract:}

This study was designed to investigate the effect of fisetin (FST) on hyperhomocysteinemia (HHcy) - induced experimental endothelial dysfunction (ED) and vascular dementia $(\mathrm{VaD})$ in rats. Eight groups of Wistar rats were randomly divided as control, vehicle control, L-methionine, FST (5, 10 and $25 \mathrm{mg} / \mathrm{kg}$, p.o.), FST-per se (25 mg/kg, p.o.) and donepezil (0.1 mg/kg, p.o.) respectively. LMethionine administration (1.7 g/kg, p.o.) for 32 days induced HHcy. ED and VaD induced by HHcy were determined by vascular reactivity measurements, behavioral analysis using Morris water maze and Y-maze along with a biochemical and histological evaluation of thoracic aorta and brain tissues. Administration of Lmethionine developed behavioral deficits, triggered brain lipid peroxidation (LPO) and compromised brain acetylcholinesterase activity (AChE) and reduced the levels of brain superoxide dismutase (SOD), brain catalase (CAT), brain reduced glutathione (GSH) and serum nitrite, increased serum homocysteine and cholesterol levels. These effects were accompanied by decreased vascular NO bioavailability, marked intimal thickening of the aorta and multiple necrotic foci in brain cortex. HHcy induced alterations in the activities of SOD, CAT, GSH, AChE, LPO, behavioral deficits, ED and histological aberrations were significantly attenuated by treatment with fisetin in a dose-dependent manner. Collectively our results indicate that fisetin exerts endothelial and neuroprotective effects against HHcy-induced ED and VaD.

Keywords: Acetylcholinesterase, Morris water maze, L-NAME, Necrotic foci, Lmethionine 


\section{Introduction}

Vascular dementia is a cognitive impairment along with dysfunction of vascular endothelium. Similar to Alzheimer's disease (AD), $\mathrm{VaD}$ results in progressive deterioration of brain functions such as memory, learning, recognition and motor function. Elevated level of homocysteine (Hcy) is an independent risk factor for $A D$ and cognitive impairment (Bottiglieri and Diaz-Arrastia 2005) which evidently shows the relation of oxidative stress mediated by free radicals due to oxidation of Hcy (Coyle and Puttfarcken 1993; Olanow 1993). Moreover, Hcy plays a pathological role in myocardial infarction, coronary artery disease, strokes, genetic disorders (Clarke et al. 1991; Schwartz et al. 1997). Hcy markedly enhances the vulnerability of neuronal cells as it is an excitatory amino acid which leads to oxidative injury (Hankey and Eikelboom 1999). L-Methionine in rats induces HHcy, which causes neurodegeneration similar to VaD like syndrome (Koladiya et al. 2008; Shah and Singh 2007) .Elevated levels of total Hcy (more than $14 \mu \mathrm{m}$ ) is termed as HHcy (Clarke et al. 1998; Seshadri 2012) which is reported to increase the risk of neurodegenerative diseases, such as $\mathrm{VaD}$, cognitive impairment or stroke (Herrmann and Obeid 2011).

Polyphenols, especially flavonoids present in plant foods act as potent antioxidants in vitro, and also they were proved for their ameliorative role in several models of VaD (Kaewkaen et al. 2012; Li et al. 2012; Ma et al. 2013; Xiong et al. 2006;). Fisetin (3, 7, 3', 4'-Tetrahydroxyflavone) (Fig. 1) is naturally abundant in fruits (e.g. strawberries, apples, grapes, mangoes, permissions, and peaches) and vegetables (e.g. onions, tomatoes and cucumbers) at concentrations of $2-160 \mu \mathrm{g} / \mathrm{g}$ (Arai et al. 2000; Pal et al. 2015). The highest concentration of fisetin was found in strawberries $(160 \mu \mathrm{g} / \mathrm{g})$ followed by apple $(26.9 \mu \mathrm{g} / \mathrm{g})$ and persimmon $(10.5 \mu \mathrm{g} / \mathrm{g})$ (Kimira et al. 1998). In the past years, fisetin was a subject of research because of it's anticancer (Suh et al. 2010), anti-inflammatory (Park et al. 2007), memory enhancing (Maher et al. 2006) and neuroprotective activities (Zbarsky et al. 2005). Fisetin is also reported for its strong antioxidant properties in membrane environments and is suggested as a potential therapeutic agent against various free radical-mediated diseases (Sengupta et al. 2004).

Although the antioxidant, anti-inflammatory, neuroprotective properties of fisetin are well established, its effect on HHcy induced endothelial dysfunction, neurotoxicity, and vascular dementia was never explored. Hence in this present 
study, we hypothesized that FST administration may have beneficial effects against $\mathrm{HHcy}$ induced neurotoxicity, endothelial dysfunction and $\mathrm{VaD}$ in rats and elucidated the possible protective mechanisms of fisetin using donepezil as a positive control.

\section{Materials and methods}

\section{Drugs and chemicals}

Fisetin (F-002) was purchased from Indofine chemicals (Hillsborough, NJ, USA). LMethionine, acetylthiocholine iodide, reduced glutathione, sodium nitroprusside, NGnitro-L-arginine methyl ester (L-NAME) and indomethacin were purchased from Sigma-Aldrich (St Louis, MO, USA). Donepezil was a gift sample from Hetero Labs Ltd., Medak district, Telangana, India. All other reagents are of analytical grade were purchased from S.D Fine Chemicals Ltd., India.

\section{Animals}

Male Wistar rats of $180-220 \mathrm{~g}$ were procured from the National Center for Laboratory Animal Sciences, National Institute of Nutrition, Hyderabad, India. All animals had free access to water ad libitum and standard laboratory pellet chow diet and maintained under standard conditions $\left(22-24{ }^{\circ} \mathrm{C}\right.$, humidity $\left.45-50 \%\right)$ on a $12 \mathrm{~h}$ light and $12 \mathrm{~h}$ dark cycle. The experiments were conducted between 9.00 and 18.00 hours under optimal conditions. Experimental protocol was approved by institutional animal ethics committee of Anurag Group of Institutions (Formerly Lalitha College of Pharmacy), and care of the animals was taken as per guidelines of the committee for the purpose and control and supervision of experiments on animals, Govt of India (Protocol No: I/IAEC/LCP/034/2013/15).

\section{Induction of HHcy}

Rats were administered with L-methionine $(1.7 \mathrm{~g} / \mathrm{kg} /$ day, p.o. for 32 days) to induce HHcy associated ED and VaD (Koladiya et al. 2008).

\section{Experimental Procedure}

Rats were divided into eight groups, and each group consists of 10 animals $(n=10)$ FST and L-methionine was freshly prepared using $0.1 \%$ dimethyl sulfoxide (DMSO) and $0.5 \%$ carboxymethylcellulose (CMC) w/v respectively, and donepezil was suspended in distilled water before administration. All the drugs were administered through the oral route. The doses of FST were selected on the basis of previous studies (Maher et al. 2006).

Group I (Control): Distilled water (10 ml/kg, p.o.) was administered once daily for four weeks, and then they were subjected to MWM test. During acquisition trial $\left(28^{\text {th }}\right.$ day 
to $31^{\text {st }}$ day) and retrieval trial $\left(32^{\text {nd }}\right.$ day), Distilled water was administered 45 min before initiation of the study.

Group II (Vehicle control): $0.1 \%$ w/v DMSO was administered once daily for 4 weeks, and then they were subjected to MWM test. During acquisition trial and retrieval trial, DMSO was administered 45 min before initiation of the study.

Group III (L-methionine): L-Methionine (1.7 g/kg/day) was administered for four weeks. L-Methionine treatment was continued (45 min before every time) during acquisition trial. The animals were administered with vehicle $0.5 \% \mathrm{w} / \mathrm{v}$ CMC (10 $\mathrm{ml} / \mathrm{kg}$, p.o.) $45 \mathrm{~min}$ before retrieval trial.

Group IV (FST-5 mg/kg): Fisetin at $5 \mathrm{mg} / \mathrm{kg} /$ day was administered from the $14^{\text {th }}$ day of L-methionine treatment for 2 weeks. The treatment was also continued during acquisition trial. The animals were administered only with vehicle (0.1\%DMSO) during retrieval trial.

Group V (FST-10 mg/kg): Fisetin at $10 \mathrm{mg} / \mathrm{kg} /$ day was administered from the $14^{\text {th }}$ day of L-methionine treatment for two weeks, and rest of the protocol was same as mentioned in group III.

Group VI (FST-25 mg/kg): Fisetin at $25 \mathrm{mg} / \mathrm{kg} /$ day was administered from the $14^{\text {th }}$ day of L-methionine treatment for two weeks, and rest of the protocol was same as mentioned in group III.

Group VII (FST-Per se): Fisetin (25 mg/kg/day) alone was administered for four weeks. The treatment was also continued during acquisition trial. The animals were administered only with vehicle (0.1\% DMSO) during retrieval trial.

Group VIII (Donepezil): Rats were administered donepezil $(0.1 \mathrm{mg} / \mathrm{kg} / \mathrm{day})$ from the $14^{\text {th }}$ day of L-methionine treatment for two weeks. The treatment was continued during acquisition trial. The animals were administered with distilled water $(10 \mathrm{ml} / \mathrm{kg}$, p.o.) during retrieval trial.

However, many studies on L-methionine-induced HHcy animal models (Koladiya et al .2008, 2009; Mangat et al. 2014; Sharma and Singh 2012) already reported the use of CMC 0.5\%/w/v CMC (10 ml/kg/p.o.) as a vehicle control which did not show any significant effects. As our experimental protocol is designed based on these earlier studies we have made an effort to reduce the number of animals and did not consider additional control group treated with $\mathrm{CMC}$. 


\section{Behavioral assessment}

Y-maze and MWM tests were carried out at the end of the fourth week after the induction of neurotoxicity ( $28^{\text {th }}$ day). The experiment was performed between $9.00 \mathrm{~h}$ - $16.00 \mathrm{~h}$ in the neuroscience laboratory at established optimal conditions.

\section{Y-Maze}

The Y-maze test is used for measuring the spatial working memory in rodents (Singh et al. 2015). The percentage of alteration is calculated as the ratio of actual alterations to possible alterations, defined as the total number of arm entries minus two, and multiplied by hundred.

\section{Morris Water Maze}

Spatial learning and memory performance were assessed using the Morris water maze test (Vorhees and Williams 2006).

\section{Acquisition trial}

The acquisition trial was carried out from $28^{\text {th }}$ to $31^{\text {st }}$ day for four times with a rest period of $1 \mathrm{~h}$ between each trial. Mean escape latency time (ELT) was calculated for each day during acquisition trials and day 4 ELT was used as an index of acquisition.

\section{Retrieval trial}

The retrieval trial was performed on the $32^{\text {nd }}$ day. The platform was removed, and the rats were placed in MWM and allowed to explore the maze for 120s. Meantime spent in all three quadrants (TSTQ) i.e. Q2, Q3 and Q4 were recorded and the time spent in the target quadrant i.e.Q1 in search of the missing platform was considered as an index for retrieval. The percentage of alterations, ELT and TSTQ were recorded and analyzed using maze master software on video tracking system (VJ Instruments, Washim, Maharashtra, India).

\section{Blood sampling and tissue preparation}

At the end of the experiment $\left(32^{\text {nd }}\right.$ day), blood samples were collected from retroorbital venipuncture and centrifuged at $3500 \mathrm{rpm}$ for $15 \mathrm{~min}$ at room temperature for separation clear, non-hemolyzed supernatant sera for homocysteine, nitrite and cholesterol estimations. Later, all rats were sacrificed by cervical dislocation and immediately brains and thoracic aorta $(n=6)$ were isolated for biochemical analysis and aortic ring assay. $10 \% \mathrm{w} / \mathrm{v}$ brain homogenate was used for acetylcholinesterase, LPO, and antioxidant estimations.

\section{Biochemical analysis}

\section{Estimation of serum biochemical parameters}


Serum Hcy was determined according to earlier described method (Kemse et al., 2014) by using Chemiluminescent Microparticle Immunoassay (Abbott Laboratory, Abbott Park, Chicago, IL). Serum nitrite was determined by using the earlier described method (Sastry et al. 2002) with slight modifications, and total cholesterol was estimated using commercially available kit (Biosystems, Costa Brava, Barcelona, Spain) on a semi-automated analyzer (Optima-S, LAB INDIA Healthcare Pvt. Ltd., Gurgaon, Haryana, India).

\section{Estimation of brain biochemical parameters}

Brain AChE was measured by using the earlier described method with slight modifications (Ellman et al. 1961). The solution containing eserine solution was used as a blank and change in absorbance was read spectrophotometrically at $420 \mathrm{~nm}$ (UV-1800 spectrophotometer; Shimadzu Co., Kyoto, Japan). Thiobarbituric acid reactive species (TBARS) was determined using the previously described method (Ohkawa et al. 1979) with slight modification. The reactive lipid peroxidation product formed was measured at $532 \mathrm{~nm}$.SOD activity was determined by the pyrogallol oxidation method (Marklund and Marklund 1974). The reaction is initiated by adding pyrogallol, and the change in optical density is measured at $420 \mathrm{~nm}$.GSH levels were measured according to the earlier described method (Ellman 1959) and absorbance was measured spectrophotometrically at $412 \mathrm{~nm}$. Catalase activity was determined by using the earlier method (Chance and Maehly 1955) with some modifications, and the breakdown of hydrogen peroxide $\left(\mathrm{H}_{2} \mathrm{O}_{2}\right)$ is measured at $240 \mathrm{~nm}$.

\section{Vascular reactivity measurements}

After decapitation and the thoracic aorta was isolated and cut into ring segments of 4 to $5 \mathrm{~mm}$ width, and mounted in an organ bath containing Krebs- bicarbonate buffer bubbled with carbonated oxygen $\left(95 \% \mathrm{O}_{2}: 5 \% \mathrm{CO}_{2}\right)$, and maintained at $37.8{ }^{\circ} \mathrm{C}$. Isometric tension developed in the vasculature was recorded by using a force transducer which was connected with a power lab data acquisition system (AD Instruments, Australia). Aortic rings were allowed to equilibrate for $30 \mathrm{~min}$ at a resting tension of $2 \mathrm{~g}$, with the bath medium changed every $10 \mathrm{~min}$. After the equilibration, aortic rings were exposed twice to $75 \mathrm{mM} \mathrm{KCl}$ to determine its maximum contractility. Each ring was washed for two to three times, re-equilibrated and allowed to relax to baseline. After $30 \mathrm{~min}$ the aortic rings were pre-contracted with phenylephrine (PHE) $\left(1 \times 10^{-6} \mathrm{M}\right)$ and exposed to (i) acetylcholine (Ach) $\left(1 \times 10^{-9}\right.$ to $1 \times 10^{-4} \mathrm{M}$ ) to assess the endothelium-dependent relaxation, a relaxation of $90 \%$ 
or more indicated the functional integrity of the endothelium (ii) sodium nitroprusside (SNP) $\left(1 \times 10^{-9}\right.$ to $\left.1 \times 10^{-4} \mathrm{M}\right)$ to assess the endothelium-independent relaxation (Pieper 1997; Shah and Singh 2006). To characterize the involvement of endothelialNO, aortic nitric oxide bioavailability was measured as a NOS inhibitor L-NAME (100 $\mathrm{mM}$ ) induced contraction of the isolated rat aorta after submaximal pre-contraction of the vessel with phenylephrine. To prevent synthesis and influence of prostaglandins, the experiment was conducted in the presence of $10 \mathrm{mM}$ indomethacin (Unger and Patil 2009).

\section{Histopathological examination}

Thoracic aorta and brain tissues $(n=4)$ were fixed in $10 \%$ phosphate-buffered formalin, processed, embedded in paraffin and sectioned to approximately $5 \mu \mathrm{m}$ thickness using a microtome (Leica, Bensheim, Germany). The aorta and brain sections were then processed and stained with hematoxylin and eosin (H\&E) for light microscopy (Axiovision software, Axioplan 2 Imaging, Zeiss microscope). Histological examination and quantification were performed by an investigator blinded to the interventions.

\section{Statistical analysis}

The contractile responses are reported as a percentage of the maximum response to $75 \mathrm{mM} \mathrm{KCl}$. The relaxation responses to ACh and SNP are reported as the percentage of relaxation of the maximum contractile response. For each concentration-response curve, the maximum effect (Emax) and the concentration of agonist that produced $50 \%$ of the maximal response (log EC50) were calculated using non-linear regression analysis (GraphPad Prism 5.0 Software, USA). The efficiency of the agonists is reported as pD2 (-log EC50). Results were expressed as mean \pm standard error of mean (S.E.M) To compare the effects of L-NAME on contractile responses to $\mathrm{PHE}$, the results were reported as "differences" in the area under the concentration-response curve (dAUC) to PHE in control, L-methionine and fisetin treated groups. AUC was calculated from the individual curve plots (GraphPad Prism 5.0 Software) and the difference was reported as a percentage of the AUC. Data of concentration-response curves was statistically analyzed using Two-way ANOVA followed by a Bonferroni post-test and all other parameters by using oneway ANOVA tests. $P<0.05$ was considered to be statistically significant. 


\section{Results}

\section{Effect of FST on y-maze activity}

In L-methionine group, there is a significant $(P<0.001)$ decrease of percentage alteration in $y$-maze when compared to the control group. However, FST administration at $5 \mathrm{mg} / \mathrm{kg}$ did not show any significant effect when compared to Lmethionine group. Further in FST $(10,25 \mathrm{mg} / \mathrm{kg})$ and donepezil-treated animals, there is a significant increase in spontaneous alteration with $(P<0.001)$ when compared to L-methionine group. FST exhibited a significant dose-dependent effect of $P<0.001$ when 10 and $25 \mathrm{mg} / \mathrm{kg}$ is compared to $5 \mathrm{mg} / \mathrm{kg}$ and $P<0.01$ when 25 $\mathrm{mg} / \mathrm{kg}$ is compared with $10 \mathrm{mg} / \mathrm{kg}$ (Table 1).

\section{Effect of FST on ELT and TSTQ of MWM}

Control group has shown a downward trend in their ELT and there was a significant fall of the day 4 ELT when compared to day 1 ELT of these rats $(P<0.001)$, reflecting normal learning ability. Further on day 5 , a significant rise in TSTQ was observed, when compared to time spent in other quadrants $(P<0.001)$ reflecting normal retrieval as well. However, L-methionine treated animals showed a significant increase in day 4 ELT when compared to day 4 ELT of the control group $(P<0.001)$ indicating impairment of acquisition. Further L-methionine administration also produced a significant decrease in day 5 TSTQ, when compared to day 5 TSTQ of the control group $(P<0.001)$ indicating impairment of memory as well. Administration of FST at $5 \mathrm{mg} / \mathrm{kg}$ did not show any significant effect when compared to Lmethionine. Further in FST $(10,25 \mathrm{mg} / \mathrm{kg})$ and donepezil-treated animals, there is a significant prevention of the rise in the day 4 ELT $(P<0.001)$ and decrease in the day 5 TSTQ in a significant manner $(P<0.001)$ indicating the reversal of Lmethionine-induced impairment of memory. FST exhibited a significant dosedependent effect of $P<0.001, P<0.05$ when 10 and $25 \mathrm{mg} / \mathrm{kg}$ is compared to 5 $\mathrm{mg} / \mathrm{kg}$ and $P<0.001$ when $25 \mathrm{mg} / \mathrm{kg}$ is compared with $10 \mathrm{mg} / \mathrm{kg}$ (Table1).

\section{Effect of FST on serum Hcy, nitrite and cholesterol levels}

In L-methionine treated group, there is a significant $(P<0.001)$ increase in serum Hcy and cholesterol level with significant $(P<0.001)$ reduction in serum nitrite levels when compared to the control group. There was a significant $(P<0.001)$ decrease in serum Hcy and cholesterol level with a significant $(P<0.001)$ increase in nitrite levels in FST-10 mg/kg, $25 \mathrm{mg} / \mathrm{kg}$ and donepezil-treated groups when compared with L-methionine. However, FST at $5 \mathrm{mg} / \mathrm{kg}$ has shown a significant reduction $(P<$ 
0.05) in cholesterol but not significant in the case of serum Hcy and nitrite. FST exhibited a significant dose-dependent effect of $P<0.05, P<0.001$ when 10 and 25 $\mathrm{mg} / \mathrm{kg}$ are compared to $5 \mathrm{mg} / \mathrm{kg}$ and $P<0.001$ when $25 \mathrm{mg} / \mathrm{kg}$ is compared with 10 $\mathrm{mg} / \mathrm{kg}$ (Table 2).

\section{Effect of FST on brain AChE activity, TBARS, and antioxidant levels}

Administration of L-methionine significantly $(P<0.001)$ increased the brain AChE and TBARS levels along with significant $(P<0.001)$ reduction in the brain $\mathrm{GSH}$, SOD, and CAT levels when compared to the control group. There was a significant $(P<0.05 ; P<0.01 ; P<0.001)$ decrease in brain AChE and TBARS levels along with significant $(P<0.01 ; P<0.001)$ increase of brain antioxidant levels in FST-10 mg/kg, FST-25 mg/kg and donepezil-treated groups when compared with L-methionine group. However, FST at $5 \mathrm{mg} / \mathrm{kg}$ has shown significant reduction $(P<0.05)$ in AChE and TBARS, along with an increase $(P<0.01)$ in SOD and CAT except GSH $(P>$ 0.05). FST showed a significant dose-dependent effect $(P<0.05, P<0.01, P<$ 0.001 ) when FST-25 mg/kg is compared to low dose and $P<0.05$ when $25 \mathrm{mg} / \mathrm{kg}$ is compared with $10 \mathrm{mg} / \mathrm{kg}$ (Table 3).

\section{Effect of FST on Vascular Reactivity}

L-Methionine treatment did not affect the response to $\mathrm{KCl}(P>0.05)$ but reduced the concentration-dependent relaxation induced by acetylcholine (Fig 2A and Table 4). However, the response induced by sodium nitroprusside did not differ between groups (Table 4 and Fig 2B). However, L-methionine administration increased the contractile responses induced by phenylephrine in the rat aortas (Fig 2C) without changing the sensitivity to this $\alpha-1$ agonist (Table 4). In aortic segments from all groups, incubation with the NOS inhibitor L-NAME (100 mM) shifted the phenylephrine concentration-response curves to the left. However, this shift was smaller in preparations from L-methionine treated rats than in control, vehicle control, FST (5, 10, 25 and Per se) and donepezil-treated rats, as shown by the \% dAUC values (Fig. 3; Table 4).

\section{Histological evaluation}

Histological evaluation of thoracic aorta revealed that L-methionine treatment in rats caused mild endothelial denuding and proliferation of smooth muscle cells and medial rupture along with the proliferation of connective tissue and disruption of normal fibrillar pattern in adventitia layer of the aorta. Further, an increase in both intima-media and intima-externa thickness is noticed in the aorta. However, FST-5 
$\mathrm{mg} / \mathrm{kg}$ treated rat aorta showed a decrease in proliferation of connective tissue and disruption of the normal fibrillar pattern along with an increase in intima-externa thickness similar to L-methionine treated group.FST (10, $25 \mathrm{mg} / \mathrm{kg}$ and Per se) and donepezil-treated groups showed normal aortic intima with the regular morphology of the aorta same as that of the control group .Further quantification of this data revealed the significant increase in aortic intima-media and intima-externa thickness in the aorta's of L-methionine and FST-5mg/kg treated groups when compared to other groups (Fig. 4).

Histological evaluation of cortical region revealed the presence of a larger area of necrotic foci in the brain parenchyma along with infiltrated lymphocytes and degenerating / apoptotic neurons. FST (5 and $10 \mathrm{mg} / \mathrm{kg}$ ) treated rat brains showed medium-sized necrotic foci in the cortical region of brain parenchyma.FST-25 mg/kg treated rat brain showed the smaller area of necrotic foci and has many neurons with normal structure. However, FST (5 and $10 \mathrm{mg} / \mathrm{kg}$ ) showed significant reduction of infiltrated lymphocytes and a similar number of degenerating / apoptotic neurons when compared to the L-methionine treated group. FST- $25 \mathrm{mg} / \mathrm{kg}$ treated rat brain showed significant reduction of infiltrated lymphocytes and degenerating / apoptotic neurons when compared to the L-methionine and FST $(5 \mathrm{mg} / \mathrm{kg})$ treated groups. FST-Per se and donepezil-treated rat cortex region showed the cytoarchitecture of neurons similar to the control group. Further quantification of this data revealed that there is a significant increase in the area, length, and width of necrotic foci, a number of degenerating/apoptotic neurons and infiltrating lymphocytes in L-methionine treated rat brain when compared to FST and donepezil-treated rat brains (Fig.5).

\section{FST- Per se effect:}

FST alone treatment $(25 \mathrm{mg} / \mathrm{kg})$ in rats did not show any significant per se effect $(P>$ 0.05 ) on all study parameters (behavioral activity, serum and brain biochemical parameters, endothelial function and histopathology) when compared with control.

\section{Discussion}

In HHcy, the thiol group of Hcy undergoes auto-oxidation to generate reactive oxygen species (ROS) and reactive nitrogen species (RNS) (especially that of nitric oxide). Further, these ROS/RNS generate other reactive species by inducing excessive lipid peroxidation thus leading to endothelial dysfunction. These deleterious effects can be neutralized either by increasing endogenous antioxidant enzyme defenses/ non-enzymatic defenses through dietary or pharmacological 
interventions. Antioxidants play an important role in the oxidation process by scavenging free radicals and diminishing oxidative stress caused due to HHcy. This defense against ROS/RNS is weakened or damaged in diseased conditions and thus increase in oxidant load. In such conditions, the external supply of antioxidants is required to counteract the deleterious effects on oxidative stress (Ratnam et al. 2006; Reuter et al. 2010). As there is much evidence that show lowering of Hcy by administration of polyphenolic antioxidants (Ataie et al. 2010; Hamelet et al. 2007; Meng et al. 2013) we hypothesized this study to evaluate the beneficial effects of dietary polyphenolic antioxidant fisetin on HHcy- induced experimental endothelial dysfunction and vascular dementia in Wistar rats.

L-Methionine administration in rats is commonly used animal model for the assessment of HHcy and its secondary complications such as ED, oxidative stress and $\mathrm{VaD}$ (Koladiya et al. 2008). In the present study, L-methionine treatment raised serum Hcy and cholesterol levels with a significant decrease in serum nitrite levels. Further, L-methionine administration markedly attenuated acetylcholine-induced endothelium-dependent relaxation; therefore, reflecting ED. In L-methionine treated animals, there is a significant impairment of acquisition and retrieval of memory, which is shown by decreased MWM and y-maze performance. Moreover, AChE levels, TBARS was enhanced and a decrease in antioxidant levels was observed.

The MWM test used in the present study is one of the widely accepted models for evaluation of spatial learning and memory (Vorhees and Williams 2006). A marked decline in the day, 4 ELT of the control group during ongoing acquisition trials denotes normal acquisition of memory, and an increase in mean TSTQ indicates retrieval of memory. A spontaneous alteration in the tendency of rats to explore a novel environment as determined by y-maze test is generally regarded as a measure of spatial memory. The alternated behavior of rodents in y-maze indicates operation of spatial working or short-term memory (Hughes 2004). The present study results on y-maze showed a decrease in percentage alterations, which reveals the index of behavioral neurotoxicity after the administration of L-methionine. Decrease in the percentage alterations in y-maze test on administration of L-methionine could be due to HHcy and its effect on impaired function of the N-methyl-D-aspartate receptor (NMDA) mediated through glutamate- Nitric Oxide/Cyclic GMP pathway in the hippocampus (Lipton et al.1997) which is involved in various forms of cognition and memory function (Obeid and Herrmann 2006). 
In the present investigation, both FST and donepezil showed significant improvement in spatial learning and memory, which is evident as an increase in the time spent in the target quadrant and decrease in escape latency time on MWM. Significant increase in the percentage of alteration in FST and donepezil-treated animals was also observed during y-maze test indicating fisetin's role on the improvement of spatial working memory. The improvement in spatial memory as measured by the two different maze tasks is dependent on hippocampus-mediated learning and memory, which is related to the NMDA receptor/Ca2+influx signaling pathway. Recent reports have revealed that flavonoids and other small molecules or drugs affect long-term potentiation and consequently, memory and cognitive performance, through their interactions with these signaling pathways (Maher 2008; Mans et al. 2010).

The degree of ED was assessed by estimating endothelial dependent and independent relaxation in aortic strips. HHcy has been reported to induce ED by decreasing the bioavailability of $\mathrm{NO}$ and by increasing vascular oxidative stress (Abahji et al. 2007). In the present study endothelial dependent and independent vascular relaxation was determined by measuring the relaxation response of acetylcholine and sodium nitroprusside on precontracted aortic ring preparation of rats from different groups. In L-methionine treated rats we observed a significant decrease in endothelium-dependent vasodilator response induced by acetylcholine however, SNP-induced relaxation was similar in animals of all groups, indicating that the ability of the vascular smooth muscle to relax in response to exogenous NO was not impaired. Moreover, we observed an increase in vasoconstrictor responses to phenylephrine and the magnitude of the response to phenylephrine was lower in the aortic rings of L-methionine treated rats. Therefore, our results suggest that the increased vascular reactivity to phenylephrine and the concomitant reduction of endothelial modulation associated with reduced acetylcholine reactivity suggest that the treatment with L-methionine reduces NO bioavailability .Previous reports have also demonstrated that HHcy induces ED (Qiu et al. 2010) by causing a decrease in bioavailability of nitric oxide and leading to increased vascular oxidative stress (Abahji et al. 2007). To investigate the hypothesis that HHcy might reduce NO bioavailability, we used a non-selective NOS inhibitor, L-NAME. Incubation with LNAME (100 mM) shifted the phenylephrine concentration-response curves to the left in aortic segments from all groups. However, this shift was smaller in preparations 
from L-methionine and FST-5mg/kg treated rats than in control and other groups, suggesting that chronic L-methionine exposure can reduce the NO bioavailability.

Nitric oxide is the most important endogenous vasodilator agent is generated by the catalysis of L-arginine by eNOS, which is a critical regulator of vascular tone (Landmesser et al. 2003). Employment of L-NAME indicated the participation of eNOS in vasorelaxation in FST, and donepezil-treated groups. Earlier studies have reported that HHcy suppressed endogenous bioavailable $\mathrm{NO}$, secondary to enhanced formation of superoxide, and attenuated vascular relaxation through impaired endothelial nitric oxide synthase (eNOS) activity in endothelial cells (Jiang et al. 2005). NO bioavailability could be diminished by the reaction of NO with superoxide anion (O2-.) or by the reaction of thiol groups in the Hcy molecule with NO. Exposure of endothelial cells to Hcy led to the formation of S-nitrosohomocysteine, decreasing the bioactivity of NO (Stamler et al. 1993). It has been reported that impairment in the normal endothelial function contributes not only to the pathogenesis of $\mathrm{VaD}$ but also to the pathogenesis and/or progression of late-onset AD (Zuliani et al. 2008). Oxidative stress and vascular dysfunction have been implicated in the pathogenesis of $\mathrm{VaD}$ and $\mathrm{AD}$ (De la Torre 2010). From our study, it is evident that FST administration showed significant dose-dependent endothelial protection and we also further determined serum Hcy, nitrite and cholesterol levels as an index of ED. This is further confirmed by a significant dose-dependent decrease in serum Hcy and cholesterol along with significant increase in nitrite levels on treatment with FST and donepezil in L-methionine treated rats.

Moreover, significant attenuation of elevated brain AChE after FST treatment $(5,10$, and $25 \mathrm{mg} / \mathrm{kg})$ may be due to its potent acetylcholinesterase inhibition. FST $(5,10$, and $25 \mathrm{mg} / \mathrm{kg}$ ) showed potent antioxidant property by causing a significant increase in the levels of GSH, SOD, CAT and ameliorated oxidative stress by decreasing the TBARS levels. In our study, FST supplementation at $5 \mathrm{mg} / \mathrm{kg}$ in Wistar rats did not show the significant $(p>0.05)$ effect when tested for behavioral parameters, serum Hcy and nitrite levels and ED in comparison with the Lmethionine treated group. However, FST showed multiple protective effects against HHcy and associated complications when it is administered at 10 and $25 \mathrm{mg} / \mathrm{kg}$ orally after L- methionine administration in rats. The administration of FST-Per se did not exhibit any significant changes in all our experimental results when compared to control. 
Donepezil is a well-known acetylcholinesterase inhibitor, which is commonly prescribed for the management of cognitive disorders. Earlier literature on donepezil suggests that in addition to its usefulness in dementia of Alzheimer's disease, it also exerts a beneficial effect in different animal models of $\mathrm{VaD}$ (Koladiya et al. 2008; Sharma and Singh 2011). Donepezil treatment in Wistar rats for two weeks has shown significant endothelial protection, which is indicated by relaxation of aortic ring preparation and increase in serum nitrite levels. Moreover, there is a significant attenuation of elevated brain AChE thus preventing excitotoxicity caused by HHcy. Donepezil is also a potent antioxidant which is confirmed by a significant increase in the levels of GSH, SOD, CAT and ameliorated oxidative stress by decreasing the TBARS levels. Now donepezil is already in use for the management of dementia of various etiologies. All our study results were well documented by histological evaluation and quantification of data from thoracic aorta and cortical regions of the brain. From our results, we observed that FST at $10 \mathrm{mg} / \mathrm{kg}$ and $25 \mathrm{mg} / \mathrm{kg}$ caused endothelial protection and showed a marked reduction in the neurodegeneration when compared to the L-methionine treated group.

There is a large body of animal behavioral evidence and human investigations to suggest that fruits in particular strawberries and blueberries are effective at reversing age-related deficits in spatial working memory (Joseph et al.1999; Krikorian et al.2010; Macready et al. 2009; Williams et al.2008). In addition to berries, pure flavonols such as quercetin, rutin (Pu et al. 2007) along with fisetin (Maher et al. 2006; Maher 2008) have also been shown to be beneficial in reversing neuronal and behavioral aging. Previous studies on other polyphenolic antioxidants suggest that reduction in homocysteine levels is seen due to improved transsulfuration of Hcy after quercetin treatment in high methionine fed rats (Meng et al. 2013) and catechin treatment in mice also significantly decreased plasma Hcy levels by enhancing hepatic cystathionine $\beta$ synthase (Hamelet et al. 2007). Although fisetin is similar to quercetin and catechin in chemical structure, there is no data so far supporting that fisetin treatment enhances transsulfuration of Hcy or hepatic CBS activity. Furthermore, FST also functions as neurotrophic factors by facilitating the growth, maintenance, regeneration, survival of nerve cells and regulation of brain function (Maher et al. 2006; Maher 2008).

Numerous reports on fisetin described that it could enhance intracellular glutathione (GSH) levels and maintain GSH levels linked with cell survival (Touil et 
al. 2011), increase intracellular glutathione levels via multiple mechanisms (Ehren and Maher 2013), and facilitate recovery from neurodegeneration by enhancing the levels of antioxidants (Ishige et al. 2001).Recent in vivo studies have identified fisetin as an orally active, novel neuroprotective and cognition-enhancing molecule. It not only has direct antioxidant activity but can also increase the levels of some major intra-cellular antioxidants. It is a small molecule that exhibited high blood-brain barrier penetrating ability, which could lead to high levels in the brain following oral administration (Maher 2009). Therefore, with support from earlier literature, and from our study results, we propose that oral administration of FST showed protective effects in a dose-dependent manner against L-methionine-induced HHcy, ED, and $\mathrm{VaD}$, which is mainly due to its memory enhancing, antioxidant, anticholinesterase, endothelial and neuroprotective effects.

In conclusion, our present findings indicate that FST has offered significant endothelial and neuroprotection in HHcy, which may attribute to its inhibition of behavioral deficits, attenuation of $\mathrm{AChE}$, lipid peroxidation, and up-regulation of endogenous antioxidant status. Furthermore, our study may provide new approaches for using dietary plant flavonoids like FST in the treatment of VaD and ED caused due to HHcy. Further studies in our laboratory are in progress to reveal the exact mechanism of Hcy and the neuroprotective properties of fisetin.

\section{Acknowledgements}

The authors thank Dr. P. Rajeshwar Reddy (Chairman, Anurag Group of Institutions, Hyderabad, India), Dr.K Raja Reddy (Research Scientist, Texas tech Univ health science center, Texas, USA) for their constant support and encouragement. Authors also thank Hetero Labs Pvt Ltd, Hyderabad, India for providing gift sample of donepezil.

Conflict of interest: All the authors declare that they have no conflict of interest associated with this study. 


\section{References:}

Abahji, T.N., Nill, L., Ide, N., Keller, C., Hoffmann, U., and Weiss, N. 2007. Acute hyperhomocysteinemia induces microvascular and macrovascular endothelial dysfunction. Arch. Med. Res .38 (4): 411-6. PMID: 17416288.

Arai, Y., Watanabe, S., Kimira, M., Shimoi, K., Mochizuki, R., and Kinae, N. 2000. Dietary intakes of flavonols, flavones and isoflavones by Japanese women and the inverse correlation between quercetin intake and plasma LDL cholesterol concentration. J.Nutr. 130(9):2243-50. PMID: 10958819.

Ataie, A., Sabetkasaei, M., Haghparast, A., Moghaddam. AH.,and Kazeminejad, B. 2010.Neuroprotective effects of the polyphenolic antioxidant agent, Curcumin, against homocysteine-induced cognitive impairment and oxidative stress in the rat. Pharmacol. Biochem. Behav.96 (4):378-85. doi: 10.1016/j.pbb.2010.06.009.

Bonetti,P,O., Lerman, L,O., and Lerman, A. 2003. Endothelial dysfunction: a marker of atherosclerotic risk. Arterioscler. Thromb. Vasc. Biol. 23 (2): 168-75. PMID: 12588755.

Bottiglieri, T., and Diaz-Arrastia, R. 2005. Hyperhomocysteinemia and cognitive function: more than just a casual link? Am. J. Clin. Nutr. 82(3):493-494.PMID: 16155257.

Chance, B., and Maehly, AC. 1955. Assay of catalase and peroxidases. Methods Enzymol.11:764- 775.

Clarke, R., Daly, L., Robinson, K., Naughten, E., Cahalane, S., Fowler, B. et al. 1991. Hyperhomocysteinemia: An Independent Risk Factor for Vascular Disease. N. Engl. J. Med. 324(17):1149-1155. doi:10.1056/NEJM19910425 3241701.

Clarke, R., Smith, A.D., Jobst, K..A., Refsum, H., Sutton, L., and Ueland, P.M. 1998. Folate, vitamin B12, and serum total homocysteine levels in confirmed Alzheimer disease. Arch. Neurol. 55(11): 1449-55. PMID:9823829.

Corzo, L., Zas, R., Rodríguez, S., Fernández-Novoa, L.,and Cacabelos, R. 2007. Decreased levels of serum nitric oxide in different forms of dementia. Neurosci. Lett .420 (3): 263-7. PMID: 17556102.

Coyle,J.T., and Puttfarcken, P. 1993. Oxidative stress, glutamate, and neurodegenerative disorders. Science, 262(5134): 689-95. PMID: 7901908.

De la Torre, J.C.2010. Vascular risk factor detection and control may prevent Alzheimer's disease. Ageing Res. Rev. 9 (3):218-25. doi:10.1016/j.arr. 2010.04.002. 
Ehren, J.L., and Maher, P. 2013.Concurrent regulation of the transcription factors Nrf2 and ATF4 mediates the enhancement of glutathione levels by the flavonoid fisetin. Biochem .Pharmacol. 85(12):1816-26. doi: 10.1016/j.bcp.2013.04.010.

Ellman, G.L. 1959.Tissue sulfhydryl groups. Arch. Biochem. Biophys. 82(1):70-77. doi: 10.1016/0003-9861(59)90090-6.

Ellman, G.L., Courtney, K.D., Andres, V.J., and Feather-Stone, R.M.1961.A new and rapid colorimetric determination of acetylcholinesterase activity. Biochem. Pharmacol.7 (2): 88-90. doi:10.1016/0006-2952(61)90145-9.

Faraci, F.M., and Lentz, S. 2004.Hyperhomocysteinemia, oxidative stress, and cerebral vascular dysfunction. Stroke, 35 (2): 345-7. PMID: 14757874.

Hamelet, J., Demuth, K., Dairou, J., Ledru, A., Paul, J.L., Dupret, J.M. et al. 2007. Effects of catechin on homocysteine metabolism in hyperhomocysteinemic mice. Biochem. Biophys. Res. Commun.355(1):221-7. PMID: 17292331.

Hankey, G.J, and Eikelboom, J.W. 1999. Homocysteine and vascular disease. Lancet, 354(9176) : 407-13. doi:10.1016/S0140-6736(98)11058-9.

Herrmann, W., and Obeid, R. 2011. Homocysteine: a biomarker in neurodegenerative diseases. Clin. Chem .Lab. Med. 49(3): 435-441. doi:10.1515/CCLM.2011.084.

Hughes, R.N. 2004. The value of spontaneous alternation behavior (SAB) as a test of retention in pharmacological investigations of memory. Neurosci. Biobehav. Rev.28 (5):497-505. PMID: 15465137.

Ishige, K., Schubert, D., Sagara, Y. 2001.Flavonoids protect neuronal cells from oxidative stress by three distinct mechanisms. Free Radic. Biol. Med.30 (4):43346. PMID: 11182299.

Jiang, X., Yang, F., Tan, H., Liao, D Bryan, R.M., Randhawa, J.K.,et al. 2005. Hyperhomocystinemia impairs endothelial function and eNOS activity via PKC activation. Arterioscler. Thromb. Vasc. Biol.25 (12):2515 -21. PMID:16210565.

Joseph, J.A., Shukitt-Hale, B., Denisova, N.A., Bielinski. D., Martin, A., McEwen, J.J., et al.1999. Reversals of age-related declines in neuronal signal transduction, cognitive, and motor behavioral deficits with blueberry, spinach, or strawberry dietary supplementation. J. Neurosci.19 (18):8114-21. PMID: 10479711.

Kaewkaen,P., Tong-un, T., Wattanathorn, J., Muchimapura, S., Kaewrueng ,W., and Wongcharoenwanakit, S. 2012. Mulberry Fruit Extract Protects against Memory Impairment and Hippocampal Damage in Animal Model of Vascular Dementia. 
Evid. Based. Complement. Alternat. Med. 2012:263520. doi: 10.1155/2012/263 520.

Kemse, N.G., Kale, A.A., and Joshi, S.R. 2014. A combined supplementation of omega-3 fatty acids and micronutrients (folic acid, vitamin B12) reduces oxidative stress markers in a rat model of pregnancy induced hypertension. PLoS One, 9(11):e111902. doi: 10.1371/journal.pone.0111902.

Kimira, M., Arai, Y., Shimoi, K., and Watanabe, S. 1998. Japanese intake of flavonoids and isoflavonoids from foods. J.Epidemiol.8 (3):168-175. PMID: 9782673.

Koladiya, R.U., Jaggi, A.S., Singh, N., and Sharma, B.K. 2008. Ameliorative role of atorvastatin and pitavastatin in I-methionine induced vascular dementia in rats. BMC Pharmacol. 8 :14. doi:10.1186/1471-2210-8-14.

Koladiya, R.U., Jaggi, A.S., Singh. N., and Sharma, B.K. 2009. Beneficial effects of donepezil on vascular endothelial dysfunction-associated dementia induced by Lmethionine in rats. J. Health Sci.55(2):215-25. doi.org/10.1248/jhs.55.215.

Krikorian, R., Nash, T.A., Shidler, MD., Shukitt-Hale, B., and Joseph, J.A. 2010.Concord grape juice supplementation improves memory function in older adults with mild cognitive impairment. Br. J. Nutr. 103(5):730-4. doi:10.1017/S0007114509992364.

Landmesser ,U., Dikalov, S., Price, S.R., McCann, L., Fukai, T., Holland, S.M., et al. 2003. Oxidation of tetrahydrobiopterin leads to uncoupling of endothelial cell nitric oxide synthase in hypertension. J. Clin. Invest. 111(8):1201-1209. PMID: 12697739.

Li, R.P., Wang, Z.Z., Sun, M.X., Hou, X.L., Sun, Y., Deng, Z.F.,et al. 2012. Polydatin protects learning and memory impairments in a rat model of vascular dementia. Phytomedicine,19(8-9):677-681.doi:10.1016/j.phymed.2012.03.002.

Lipton, S.A., Kim, W.K., Choi, Y.B., Kumar, S., D'Emilia, D.M., Rayudu,D.R., et al.1997. Neurotoxicity associated with dual actions of HCY at the N-methyl-Daspartate receptor. Proc. Natl. Acad. Sci. U.S.A. 94 (11): 5923-5928. PMID:9159176.

Luscher, T.F., Raij, L., and Vanhoutte, P.M.1987. Endothelium-dependent vascular responses in normotensive and hypertensive Dahl rats. Hypertension, 9 (2): 15763. PMID: 3818012.

Ma ,X., Sun ,Z., Liu, Y., Jia, Y., Zhang, B., and Zhang, J. 2013. Resveratrol improves 
cognition and reduces oxidative stress in rats with vascular dementia. Neural. Regen. Res.8(22): 2050-9. doi:10.3969/j.issn.1673-5374.2013.22.004.

Macready, A.L., Kennedy, O.B., Ellis, J.A., Williams, C.M., Spencer, J.P., and Butler, L.T. 2009.Flavonoids and cognitive function: A review of human randomized controlled trial studies and recommendations for future studies. Genes Nutr. 4(4):227-42. doi: 10.1007/s12263-009-0135-4

Maher ,P., Akaishi, T., and Abe, K. 2006. Flavonoid fisetin promotes ERK-dependent long-term potentiation and enhances memory. Proc. Natl .Acad. Sci .U.S.A. 103(44) :16568-16573. PMID: 17050681.

Maher, P. 2008. The flavonoid fisetin promotes nerve cell survival from trophic factor withdrawal by enhancement of proteasome activity. Arch. Biochem. Biophys.476 (2): 139-44. doi: 10.1016/j.abb.2008.03.023.

Maher, P.2009. Modulation of multiple pathways involved in the maintenance of neuronal function during aging by fisetin. Genes Nutr.4 (4): 297-307. doi: $10.1007 / \mathrm{s} 12263-009-0142-5$.

Mangat, G.S., Jaggi, A.S., and Singh, N. 2014. Ameliorative effect of a selective endothelin ETA receptor antagonist in rat model of L-methionine-induced vascular dementia. Korean J. Physiol. Pharmacol.18 (3):201-9. doi: 10.4196/kjpp. 2014. 18.3.201.

Mans, A., Chowdhury, N., Cao, D., McMahon, L.L., and Li, L. 2010. Simvastatin enhances hippocampal long-term potentiation in C57BL/6 mice. Neuroscience, 166 (2): 435-444. doi: 10.1016/j.neuroscience.2009.12.062.

Marklund,S., and Marklund, G. 1974.Involvement of the superoxide anion radical in the autoxidation of pyrogallol and a convenient assay for superoxide dismutase. Eur.J.Biochem .47(3):469-474. PMID: 4215654.

Meng. B., Gao, W., Wei, J., Yang, J., Wu, J., Pu, L., et al.2013. Quercetin reduces serum homocysteine level in rats fed a methionine-enriched diet. Nutrition, 29(4):661-6. doi: 10.1016/j.nut.2012.10.012.

Obeid. R., and Herrmann, W. 2006. Mechanisms of homocysteine neurotoxicity in neurodegenerative diseases with special reference to dementia. FEBS Lett.580 (13):2994 - 3005. PMID:16697371. 
Ohkawa ,H., Ohishi, N., and Yagi ,K.1979. Assay for lipid peroxides in animal tissues by thiobarbituric acid reaction. Anal. Biochem. 95(2):351-358. doi: 10.1016/00032697(79)90738-3.

Olanow, C.W. 1993. A rationale for monoamine oxidase inhibition as neuroprotective therapy for parkinson's disease. Mov. Disord. 8 (S1): S1-S7. doi:10.1002/ mds.870080503.

Pal, H.C., Athar, M., Elmets, C.A., and Afaq, F.2015. Fisetin inhibits UVB-induced cutaneous inflammation and activation of PI3K/AKT/NF-kB signaling pathways in SKH-1 hairless mice. Photochem. Photobiol. 91(1):225-34. doi: 10.1111/php. 12337.

Park, H.H., Lee, S., Oh, J.M., Lee, M.S., Yoon, K.H., Park, BH, et al. 2007.Antiinflammatory activity of fisetin in human mast cells (HMC-1). Pharmacol. Res.55: 31-37. PMID: 17079162.

Pieper, G.M, Langenstroer, P., and Siebeneich, W.1997. Diabetic induced endothelial dysfunction in rat aorta: role of hydroxyl radicals. Cardiovasc. Res. 34(1): 145-156. PMID: 9217884.

Pu ,F., Mishima, K., Irie, K., Motohashi, K., Tanaka, Y., Orito, K., et al. 2007.Neuroprotective effects of quercetin and rutin on spatial memory impairment in an 8-arm radial maze task and neuronal death induced by repeated cerebral ischemia in rats. J. Pharmacol. Sci.104 (4):329-34 PMID: 17666865.

Qiu, L.H., Xie, X.J., and Zhang, BQ. 2010. Astragaloside IV improves homocysteineinduced acute phase endothelial dysfunction via antioxidation. Biol. Pharm. Bull. 33 (4): 641-6. PMID:20410599.

Ratnam, D.V, Ankola, D.D., Bhardwaj , V., Sahana, D.K., and Kumar, M.N. 2006. Role of antioxidants in prophylaxis and therapy: a pharmaceutical perspective. $J$ Control. Release, 113 (3):189-207. PMID: 16790290.

Reuter, S., Gupta, S.C., Chaturvedi, M.M., and Aggarwal, B.B. 2010. Oxidative stress, inflammation, and cancer: how are they linked? Free Radic. Biol. Med.49 (11):1603-16. doi: 10.1016/j.freeradbiomed.2010.09.006.

Sastry, K.V.H., Moudgal, R.P., Mohan, J., Tyagi, J.S., and Rao, G.S.S. 2002. Spectrophotometric determination of serum nitrite and nitrate by copper-cadmium alloy. Anal.Biochem. 306(1):79-82. PMID: 12069417.

Schwartz, S.M, Siscovick, D.S, Malinow, M.R., Rosendaal, F.R., Beverly, R.K., Hess, D.L., et al. 1997. Myocardial infarction in young women in relation to plasma total 
homocysteine, folate, and a common variant in the methylenetetrahydrofolate reductase gene. Circulation, 96 (2), 412-7. PMID: 9244205.

Sengupta, B., Banerjee, A., and Sengupta, P.K. 2004.Investigations on the binding and antioxidant properties of the plant flavonoid fisetin in model biomembranes. FEBS Lett. 570(1-3):77-81. PMID: 15251443.

Seshadri, S. 2012. Homocysteine and the risk of dementia. Clin. Chem. 58(6): 105960. doi:10.1373/clinchem.2011.181099.

Shah, D.I., and Singh, M. 2007. Possible role of Akt to improve vascular endothelial dysfunction in diabetic and hyperhomocysteinemic rats. Mol. Cell. Biochem. 295(1-2) :65-74. doi:10.1007/s11010-006-9273-9.

Shah, D.I., and Singh, M. 2006. Inhibition of protein tyrosine phosphatase improves vascular endothelial dysfunction. Vascul. Pharmacol .44(3): 177- 182. PMID: 16442349.

Sharma, B., and Singh, N. 2011.Behavioral and biochemical investigations to explore pharmacological potential of PPAR-gamma agonists in vascular dementia of diabetic rats. Pharmacol Biochem Behav.100 (2):320-9. doi: 10.1016/ j.pbb.2011.08.020.

Sharma, B., and Singh, N. 2012. Salutary effect of NFKB inhibitor and folacin in hyperhomocysteinemia-hyperlipidemia induced vascular dementia. Prog. Neuropsychopharmacol. Biol. Psychiatry, 38 (2):207-215. doi: 10.1016/j.pnpbp. 2012.03 .013$.

Singh, J.C., Kakalij ,R.M., Kshirsagar, R.P., Kumar, B.H., Komakula, S.S.,and Diwan, P.V. 2015. Cognitive effects of vanillic acid against streptozotocin-induced neurodegeneration in mice. Pharm. Biol. 53 (5):630-6. doi:10.3109/13880209 .2014 .935866 .

Stamler, J.S., Osborne, J.A., Jaraki, O., Rabbani, L.E., Mullins, M., Singel, D.,et al. 1993. Adverse vascular effects of homocysteine are modulated by endotheliumderived relaxing factor and related oxides of nitrogen. J. Clin. Invest .91(1):308318. PMID: 8380812.

Suh, Y., Afaq, F., Khan, N., Johnson, J.J, Khusro, F.H., and Mukhta, H. 2010. Fisetin induces autophagic cell death through suppression of mTOR signaling pathway in prostate cancer cells. Carcinogenesis, 31:1424-1433. doi: 10.1093/carcin/bgq115. Touil, Y.S., Auzeil,N., Boulinguez, F., Saighi, H., Regazzetti ,A., Scherman, D.,et al. 2011. Fisetin disposition and metabolism in mice: Identification of geraldol as an 
active metabolite. Biochem. Pharmacol. 82(11):1731-9.doi:10.1016/j.bcp.2011 07.097.

Unger, B.S., and Patil, B.M. 2009. Apocynin improves endothelial function and prevents the development of hypertension in fructose fed rat. Indian J. Pharmacol. 41(5):208-12. doi: 10.4103/0253-7613.58508.

Vorhees, C.V, and Williams, M.T.2006. Morris water maze: Procedures for assessing spatial and related forms of learning and memory. Nat. Protoc. 1(2): 848-858. PMID: 17406317.

Williams, C.M.,EIMohsen, M.A., Vauzou, D., Rendeiro, C., Butler, L.T., Ellis, J.A. et al. 2008. Blueberry-induced changes in spatial working memory correlate with changes in hippocampal CREB phosphorylation and brain-derived neurotrophic factor (BDNF) levels. Free Radic. Biol. Med. 45(3):295-305. doi: 10.1016/j.free radbiomed.2008.04.008.

Xiong, Z., Liu, C., Wang, F., Li ,C., Wang, W., Wang, J., et al. 2006. Protective Effects of Breviscapine on Ischemic Vascular Dementia in Rats. Biol. Pharm. Bull. 29 (9): 1880-5. PMID: 16946502.

Zbarsky, V., Datla, K.P., Parkar, S., Rai, D.K., Aruoma, O.I., and Dexter, D.T. 2005. Neuroprotective properties of the natural phenolic antioxidants curcumin and naringenin but not quercetin and fisetin in a 6-OHDA model of Parkinson's disease. Free Radic. Res.39 (10): 1119-25. PMID: 16298737.

Zuliani, G., Cavalieri, M., Galvani, M., Passaro, A., Munari, M.R., Bosi, C., et al. 2008. Markers of endothelial dysfunction in older subjects with late onset Alzheimer's disease or vascular dementia. J. Neurol. Sci. 272 (1-2): 164-70. doi: 10.1016/j.jns.2008.05.020. 


\section{Tables:}

Table 1: Effect of FST administration on ELT, TSTQ and percentage alterations of MWM and Y-maze in Wistar rats. Values are expressed as mean \pm SEM $(n=10)$. Superscript letters represent the statistical significance done by ANOVA, followed by Tukey's multiple comparison tests. ${ }^{\text {b }}, P<0.001$ when compared with Day1 ELT; ${ }^{a}, P<0.001$ when compared with the control; ${ }^{\mathbf{c}, \mathbf{d}, \mathbf{e}}$ , $P<0.001$ when compared with L-methionine treated rats; ${ }^{\mathrm{f}}, P<0.05,{ }^{\mathrm{g}}, P<0.001$ indicates dose dependent effect when compared with FST-5 mg/kg; ${ }^{\mathrm{h}}, P<0.01,{ }^{\mathrm{i}}, P<0.001$ indicates dose dependent effect when compared with FST-10 mg/kg.

\begin{tabular}{|c|c|c|c|c|}
\hline \multirow[t]{2}{*}{ Groups } & \multicolumn{3}{|c|}{ Morris water maze } & \multirow{2}{*}{$\begin{array}{l}\text { Y-maze } \\
\text { Percentage } \\
\text { alterations }\end{array}$} \\
\hline & $\begin{array}{l}\text { Escape latency } \\
\text { (sec) Day } 1\end{array}$ & $\begin{array}{l}\text { Escape latency } \\
\text { (sec) Day } 4\end{array}$ & $\begin{array}{l}\text { Time spent in } \\
\text { target quadrant (sec) Day } 5\end{array}$ & \\
\hline $\begin{array}{l}\text { Control } \\
\text { Vehicle control } \\
\text { L-methionine } \\
\text { FST-5 } \mathrm{mg} / \mathrm{kg} \\
\text { FST-10 } \mathrm{mg} / \mathrm{kg} \\
\text { FST-25 } \mathrm{mg} / \mathrm{kg} \\
\text { FST-Per se }\end{array}$ & $\begin{array}{l}84.19 \pm 2.04 \\
89.19 \pm 2.06 \\
113.8 \pm 3.32 \\
101.2 \pm 1.66 \\
89.53 \pm 1.26 \\
88.05 \pm 1.01 \\
81.83 \pm 1.99\end{array}$ & $\begin{array}{l}42.67 \pm 2.96^{\mathrm{b}} \\
41.50 \pm 2.99^{-} \\
75.33 \pm 1.45^{\mathrm{a}} \\
71.50 \pm 2.04^{\mathrm{f}} \\
61.58 \pm 0.91^{\mathrm{c}, \mathrm{f}} \\
48.29 \pm 3.08^{\mathrm{d}, \mathrm{g}, \mathrm{i}} \\
37.50 \pm 1.43\end{array}$ & $\begin{array}{l}67.90 \pm 3.18 \\
61.60 \pm 1.53 \\
20.90 \pm 1.26^{\mathrm{a}} \\
22.10 \pm 1.38 \\
41.70 \pm 1.11^{\mathrm{c}, \mathrm{g}} \\
56.60 \pm 2.24^{\mathrm{d}, \mathrm{g}, \mathrm{i}} \\
67.50 \pm 1.32\end{array}$ & $\begin{array}{l}60.60 \pm 2.11 \\
59.71 \pm 1.35 \\
20.68 \pm 1.53^{\mathrm{a}} \\
22.34 \pm 1.15 \\
33.67 \pm 1.20^{\mathrm{c}, \mathrm{g}} \\
42.78 \pm 1.23^{\mathrm{d}, \mathrm{g}, \mathrm{h}} \\
52.18 \pm 2.10\end{array}$ \\
\hline Donepezil & $82.83 \pm 1.07$ & $40.53 \pm 1.04^{\mathrm{e}}$ & $69.00 \pm 1.67^{\mathrm{e}}$ & $51.02 \pm 2.01^{\mathrm{e}}$ \\
\hline
\end{tabular}


Table 2: Effect of FST administration on serum homocysteine, nitrite and cholesterol in Wistar rats. Values are expressed as mean \pm SEM $(n=6)$. Superscript letters represent the statistical significance done by ANOVA, followed by Tukey's multiple comparison tests. ${ }^{a}, P<0.001$ when compared with control; ${ }^{\mathrm{b}}, P<0.05,{ }^{\mathrm{c}}, P<0.01$, $,{ }^{\mathrm{d}}, P<0.001$ when compared with ${ }^{-}$, methionine treated group ; ${ }^{\mathrm{f}}, P<0.05,{ }^{\mathrm{g}}, P<0.001$ indicates dose dependent activity when compared with $\mathrm{FST}-5 \mathrm{mg} / \mathrm{kg} .{ }^{\mathrm{h}}, P<$ 0.001 indicates dose dependent activity when compared with FST-10 mg/kg.

\begin{tabular}{|c|c|c|c|}
\hline Groups & Serum homocysteine $(\mu \mathrm{g} / \mathrm{ml})$ & Serum nitrite( $\mathrm{Mm} / \mathrm{ml})$ & Serum cholesterol (mg/dl) \\
\hline Control & $8.41 \pm 0.49$ & $14.90 \pm 0.70$ & $97.00 \pm 1.75$ \\
\hline Vehicle control & $7.70 \pm 0.94$ & $14.22 \pm 1.25$ & $93.67 \pm 3.78$ \\
\hline L-methionine & $20.79 \pm 1.75^{a}$ & $4.42 \pm 0.32^{a}$ & $190.8 \pm 3.32^{a}$ \\
\hline FST-5 mg/kg & $19.12 \pm 0.98$ & $6.60 \pm 0.75$ & $172.8 \pm 3.96^{b}$ \\
\hline FST-10 $\mathrm{mg} / \mathrm{kg}$ & $14.61 \pm 1.46^{\mathrm{c}}$ & $10.80 \pm 1.52^{c}$ & $148.8 \pm 2.98^{\mathrm{c}, \mathrm{g}}$ \\
\hline FST-25 mg/kg & $10.56 \pm 0.52^{d, g}$ & $11.61 \pm 1.04^{\mathrm{d}, \mathrm{f}}$ & $107.5 \pm 2.89^{\mathrm{d}, \mathrm{g}, \mathrm{h}}$ \\
\hline FST-Per se & $8.50 \pm 0.78$ & $13.67 \pm 0.73$ & $91.83 \pm 3.90$ \\
\hline Donepezil & $7.32 \pm 0.86^{\mathrm{e}}$ & $13.74 \pm 1.39^{\mathrm{e}}$ & $102.3 \pm 4.14^{\mathrm{e}}$ \\
\hline
\end{tabular}


Table 3: Effect of FST administration on brain AChE, TBARS and antioxidants in Wistar rats. Values are expressed as mean \pm SEM $(n=6)$. Superscript letters represent the statistical significance done by ANOVA, followed by Tukey's multiple comparison tests. ${ }^{a} P<0.001$ when compared with control; ${ }^{\mathrm{b}}, P<0.05,{ }^{\mathrm{c}}, P<0.01,{ }^{\mathrm{d}}, \mathrm{e}, P<0.001$ when compared with L- methionine treated group ; ${ }^{\mathrm{f}}, P<0.05^{\mathrm{g}}, P<0.01,{ }^{\mathrm{h}}, P<0.001$ indicates dose dependent activity when compared with $\mathrm{FST}-5 \mathrm{mg} / \mathrm{kg}$. ${ }^{\mathrm{i}}, P<0.05$ indicates dose dependent activity when compared with FST-10 mg/kg.

\begin{tabular}{|c|c|c|c|c|c|c|c|c|}
\hline $\begin{array}{l}\text { Biochemical } \\
\text { parameters }\end{array}$ & Control & $\begin{array}{l}\text { Vehicle } \\
\text { control }\end{array}$ & L-methionine & $\begin{array}{l}\text { FST- } 5 \\
\text { mg/kg }\end{array}$ & $\begin{array}{l}\text { FST-10 } \\
\mathrm{mg} / \mathrm{kg}\end{array}$ & FST-25 mg/kg & FST- Per se & Donepezil \\
\hline $\begin{array}{l}\text { AChE } \\
\text { ( } \mu \mathrm{M} / \mathrm{mg} \text { protein) }\end{array}$ & $8.81 \pm 0.73$ & $9.67 \pm 1.18$ & $25.93 \pm 2.37^{a}$ & $19.28 \pm 1.49^{b}$ & $14.26 \pm 1.45^{d}$ & $10.23 \pm 0.91^{\mathrm{d}, \mathrm{g}}$ & $8.05 \pm 1.12$ & $6.09 \pm 1.44^{\mathrm{e}}$ \\
\hline $\begin{array}{l}\text { TBARS } \\
\text { (nM/mg } \\
\text { protein) }\end{array}$ & $6.74 \pm 0.51$ & $6.36 \pm 0.83$ & $15.25 \pm 1.65^{a}$ & $10.65 \pm 0.52^{b}$ & $7.94 \pm 0.62^{d}$ & $6.21 \pm 0.71^{\mathrm{d}, \mathrm{f}}$ & $5.46 \pm 0.39$ & $4.94 \pm 0.80^{\mathrm{e}}$ \\
\hline $\begin{array}{l}\text { GSH }(\mu \mathrm{M} / \mathrm{mg} \\
\text { protein) }\end{array}$ & $21.29 \pm 0.94$ & $20.49 \pm 0.99$ & $8.00 \pm 0.75^{a}$ & $12.19 \pm 0.73$ & $15.90 \pm 0.78^{d}$ & $20.33 \pm 1.03^{\mathrm{d}, \mathrm{h}, \mathrm{i}}$ & $21.39 \pm 0.86$ & $22.32 \pm 1.37^{\mathrm{e}}$ \\
\hline $\begin{array}{l}\text { SOD } \\
\text { (U/min/mgprotein) }\end{array}$ & $10.48 \pm 0.69$ & $9.43 \pm 0.83$ & $2.74 \pm 0.47^{a}$ & $6.37 \pm 0.47^{c}$ & $8.51 \pm 0.49^{d}$ & $9.56 \pm 0.21^{d, f}$ & $9.12 \pm 1.11$ & $9.79 \pm 0.51^{\mathrm{e}}$ \\
\hline $\begin{array}{l}\text { Catalase } \\
\text { ( } \mu \mathrm{g} / \mathrm{mg} \text { protein) }\end{array}$ & $3.05 \pm 0.30$ & $2.36 \pm 0.15$ & $0.83 \pm 0.22$ & $1.98 \pm 0.18^{c}$ & $2.57 \pm 0.15^{d}$ & $2.84 \pm 0.30^{d}$ & $3.26 \pm 0.16$ & $3.32 \pm 0.41^{\mathrm{e}}$ \\
\hline
\end{tabular}


Table 4: Maximal responses (Emax) and Sensitivity (pD2) to acetylcholine, sodium nitroprusside, phenylephrine and effect of L-NAME to phenylephrine in aortic rings of wistar rats. Values are expressed as mean \pm SEM ( $n=6)$. Emax, maximal effect expressed as a percentage of the response induced by $75 \mathrm{mM} \mathrm{KCl}$; pD2, -log one-half Emax. Superscript letters represent the statistical significance done by ANOVA, followed by Dunnett's Multiple Comparison Test. ${ }^{\mathrm{a}}, P<0.001,{ }^{\mathrm{b}}, P<0.01,{ }^{\mathrm{c}}, P<0.05$, when compared with control group.

\begin{tabular}{|c|c|c|c|c|c|c|c|c|}
\hline \multirow[t]{2}{*}{ Groups } & \multicolumn{2}{|c|}{ Acetyl choline } & \multicolumn{2}{|c|}{ Sodium nitroprusside } & \multicolumn{2}{|c|}{ Phenylephrine } & \multicolumn{2}{|c|}{ L-NAME } \\
\hline & $\operatorname{Emax}(\%)$ & pD2 & $\operatorname{Emax}(\%)$ & pD2 & Emax (\%) & pD2 & $\operatorname{Emax}(\%)$ & pD2 \\
\hline Control & $104.8 \pm 2.73$ & $6.71 \pm 0.08$ & $92.06 \pm 2.62$ & $6.68 \pm 0.09$ & $89.48 \pm 2.95$ & $6.07 \pm 0.09$ & $127.0 \pm 3.21$ & $7.04 \pm 0.08$ \\
\hline Vehicle control & $111.1 \pm 3.12$ & $6.70 \pm 0.09$ & $93.72 \pm 2.63$ & $6.63 \pm 0.10$ & $90.92 \pm 4.34$ & $6.45 \pm 0.15$ & $125.8 \pm 1.95$ & $7.36 \pm 0.05^{c}$ \\
\hline L-methionine & $71.89 \pm 1.99^{a}$ & $7.40 \pm 0.10^{\mathrm{a}}$ & $94.27 \pm 2.02$ & $6.86 \pm 0.10$ & $129.7 \pm 2.52^{\mathrm{a}}$ & $6.62 \pm 0.062^{b}$ & $164.9 \pm 4.01^{a}$ & $6.75 \pm 0.08$ \\
\hline FST-5 mg/kg & $88.09 \pm 2.17^{a}$ & $7.12 \pm 0.08^{c}$ & $92.71 \pm 2.04$ & $6.83 \pm 0.08$ & $99.62 \pm 3.11$ & $6.82 \pm 0.10^{a}$ & $150.2 \pm 2.48^{a}$ & $6.87 \pm 0.05$ \\
\hline FST-10 mg/kg & $94.38 \pm 2.31^{\mathrm{c}}$ & $7.38 \pm 0.09^{a}$ & $93.66 \pm 2.85$ & $6.64 \pm 0.09$ & $93.85 \pm 3.45$ & $6.57 \pm 0.11^{\mathrm{c}}$ & $136.0 \pm 2.76$ & $7.08 \pm 0.07$ \\
\hline $\begin{array}{l}\text { FST-25 mg/kg } \\
\text { FST-Per se }\end{array}$ & $\begin{array}{l}95.82 \pm 2.71 \\
109.0 \pm 3.13\end{array}$ & $\begin{array}{l}7.13 \pm 0.10^{c} \\
6.73 \pm 0.09\end{array}$ & $\begin{array}{l}93.18 \pm 2.34 \\
93.00 \pm 2.27\end{array}$ & $\begin{array}{l}6.67 \pm 0.10 \\
6.62 \pm 0.10\end{array}$ & $\begin{array}{l}89.21 \pm 3.07 \\
89.87 \pm 2.69\end{array}$ & $\begin{array}{l}6.17 \pm 0.10 \\
6.15 \pm 0.08\end{array}$ & $\begin{array}{l}133.8 \pm 3.74 \\
130.5 \pm 3.18\end{array}$ & $\begin{array}{l}6.94 \pm 0.09 \\
7.05 \pm 0.08\end{array}$ \\
\hline Donepezil & $106.3 \pm 2.87$ & $6.84 \pm 0.09$ & $92.35 \pm 2.34$ & $6.67 \pm 0.10$ & $92.01 \pm 3.32$ & $6.16 \pm 0.10$ & $129.1 \pm 3.34$ & $7.05 \pm 0.08$ \\
\hline
\end{tabular}




\section{Figure Captions:}

Fig. 1: Chemical structure of Fisetin (3,7,3',4'-Tetrahydroxyflavone)

Fig. 2: Effect of fisetin administration on the vascular relaxation and vasoconstrictor response. Concentration-response curves to acetylcholine (A), sodiumnitroprusside (B) and phenylephrine (C). Two-way ANOVA followed by a Bonferroni post test. ${ }^{\mathrm{a}} P<0.001$; ${ }^{\mathrm{b}} P<0.05$; ${ }^{\text {ns }} P>0.05$ when compared with Lmethionine treated group. The number of animals used is indicated in parentheses.

Fig. 3: Phenylephrine concentration-response curves after $\mathbf{N}$-nitro-L-arginine methyl ester incubation (L-NAME, $100 \mathrm{mM}$ ) (A-H). Two-way ANOVA followed by a Bonferroni post test. ${ }^{a} P<0.001$ when compared with $L-$ methionine treated group. The number of animals used is indicated in parentheses. Differences in the area under the concentration-response curves (dAUC) in the presence and absence of LNAME (I). One-way ANOVA, followed by Tukey's multiple comparison tests. ${ }^{a} P<$ $0.001 ;{ }^{\mathrm{b}} P<0.01 ;{ }^{\mathrm{c}} P<0.05 ;{ }^{\text {ns }} P>0.05$ when compared with L- methionine treated group.

Fig. 4: Histological examination of the thoracic aorta, H\&E 100x.

A, B-Control and vehicle control treated rat thoracic aorta showing normal architecture with regular vascular morphology.

C- L-Methionine treated group showing Mild Endothelial Denuding (MEDN) and proliferation of Smooth Muscle Cells (PSMC) and medial rupture * indicates proliferation of connective tissue and disruption of normal fibrillar pattern in adventia layer of aorta.Increase in intima-media thickness and intima-externa thickness is also noticed. H\&E 200x

D- D-FST-5 mg/kg group showing decrease in proliferation of connective tissue and disruption of normal fibrillar pattern when compared to L-methionine group. Further an increase in intima-externa thickness is noticed in the aorta (black arrows).

E-H-FST-10,25 mg/kg,Per se and Donepezil treated groups showing normal aortic intima with regular morphology of the aorta same as the control group.

I- Quantitative analysis of Intima -media thickness.

K- Quantitative analysis of Intima -externa thickness.

Data represent mean \pm SEM from four different animals.One-way ANOVA, followed

by Dunnett's Multiple Comparison Test. ${ }^{a} p<0.01$ vs L-methionine group (scale bars- $100 \mu \mathrm{m})$.

Fig. 5: Histological examination of rat brain cortex, H\&E $200 x$.

A, B- Control and vehicle control treated rat brain cortex showing cytoarchitecture of normal neurons.

C- L-Methionine treated rat cortical region showing larger area of necrotic foci in brain parenchyma along with lymphocyte infiltration and presence of degenerating / apoptotic neurons.

D, E- FST-5 and $10 \mathrm{mg} / \mathrm{kg}$ group rat brain showing medium sized necrotic foci in the cortical region of brain parenchyma. Lymphocyte infiltration and presence of degenerating / apoptotic neurons similar to L-methionine treated group were observed. 
F- FST-25 mg/kg showing smaller area of necrotic foci and has many neurons with normal structure. Marked reduction in infiltrating lymphocytes and degenerating / apoptotic neurons was noticed.

G, H- FST-Per se and donepezil-treated rat cortex region showing cytoarchitecture of neurons similar to the control group.

I-K- Quantitative analysis of the area of necrotic foci, length and width of necrotic foci and number of degenerated neurons and infiltrated lymphocytes in L-methionine and drug treated groups.

Data represent mean \pm SEM from four different animals. One-way ANOVA, followed by Dunnett's Multiple Comparison Test. ${ }^{a} P<0.001$; ${ }^{b} p<0.01$; ns $p>0.05$ vs L-

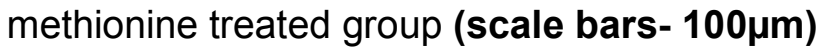




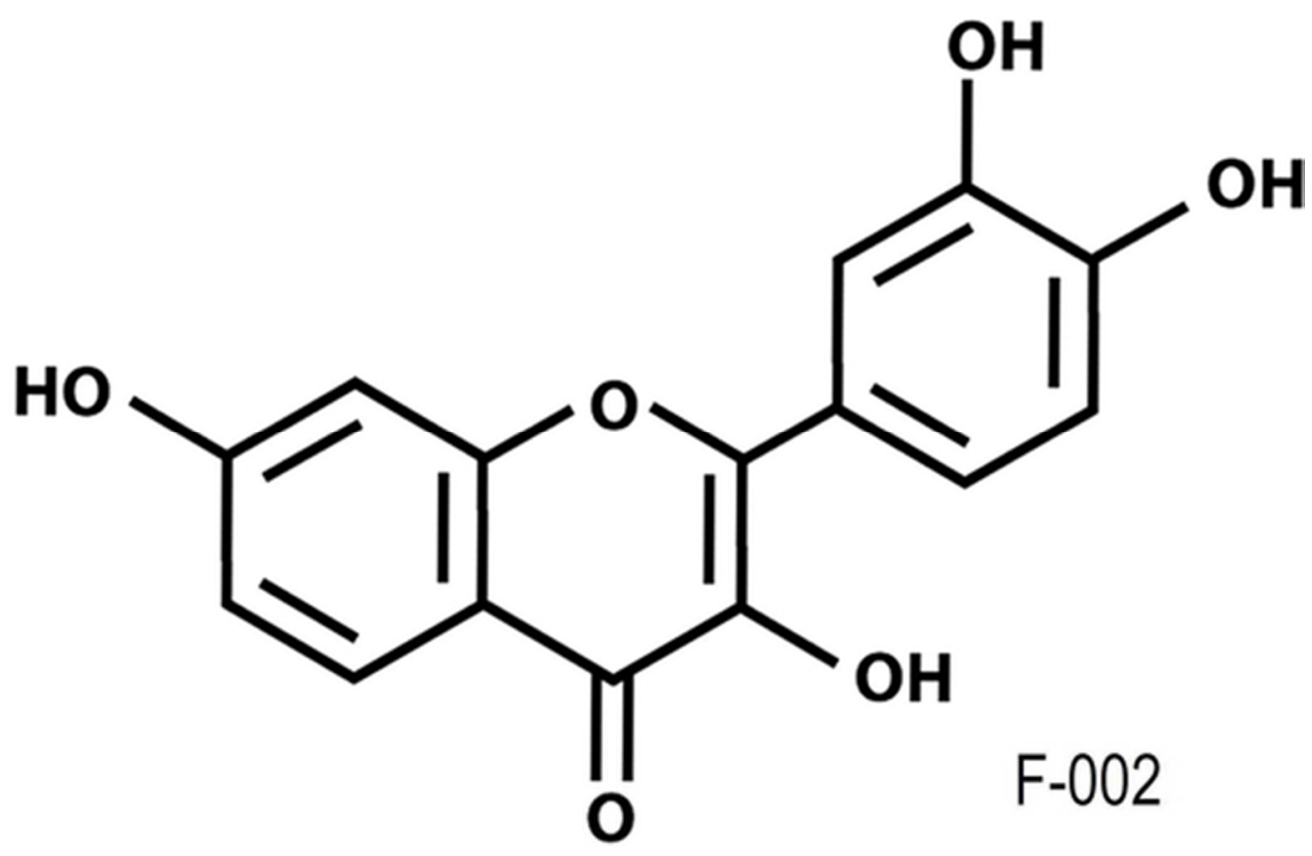

Fig. 1

$48 \times 30 \mathrm{~mm}(300 \times 300 \mathrm{DPI})$ 

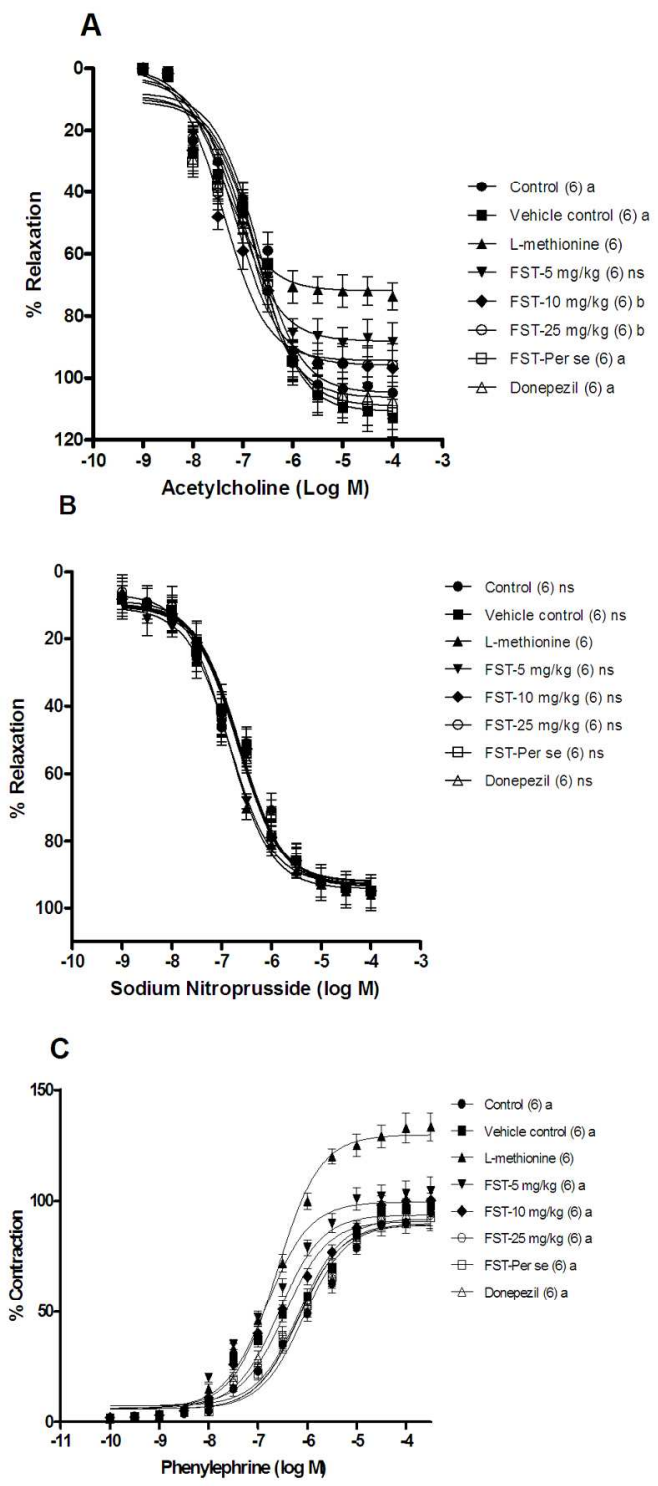

Fig. 2 

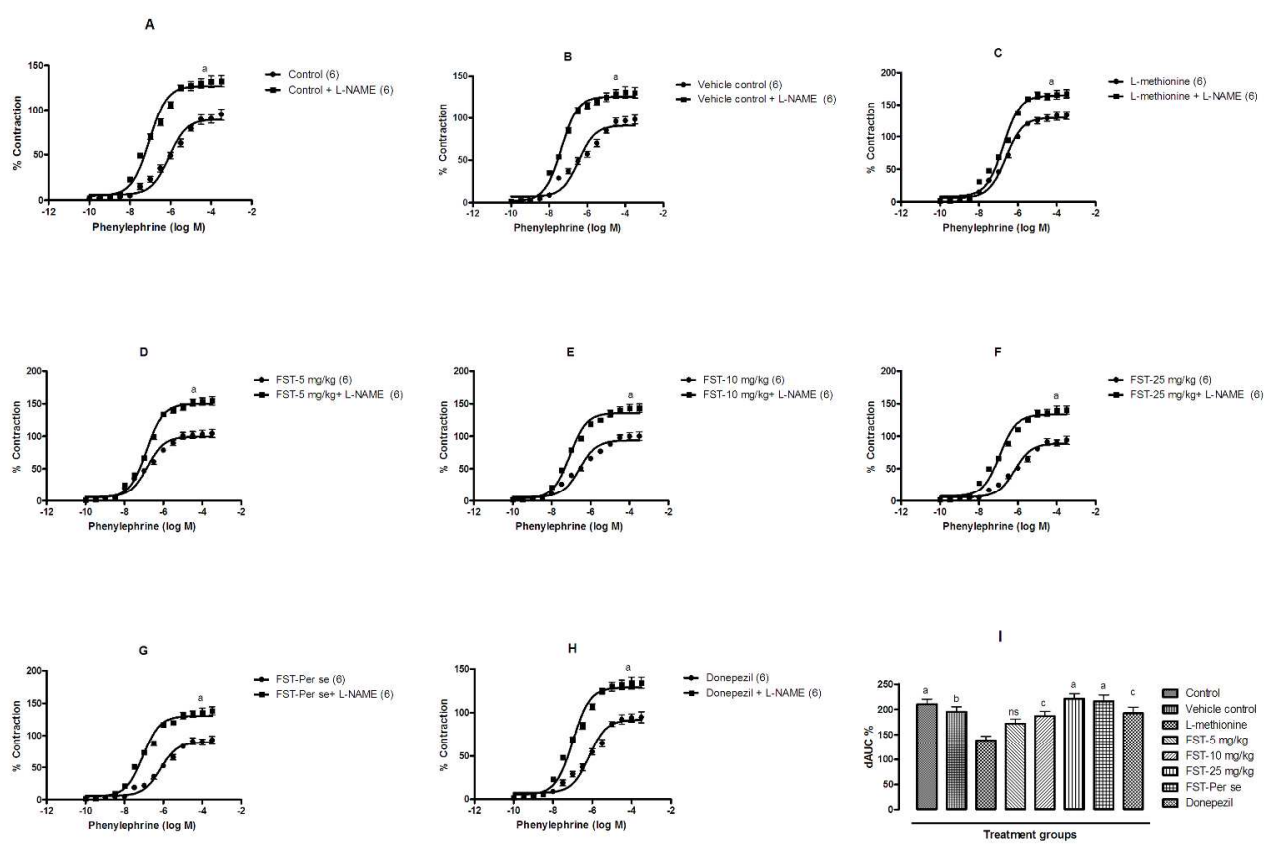

Fig. 3 


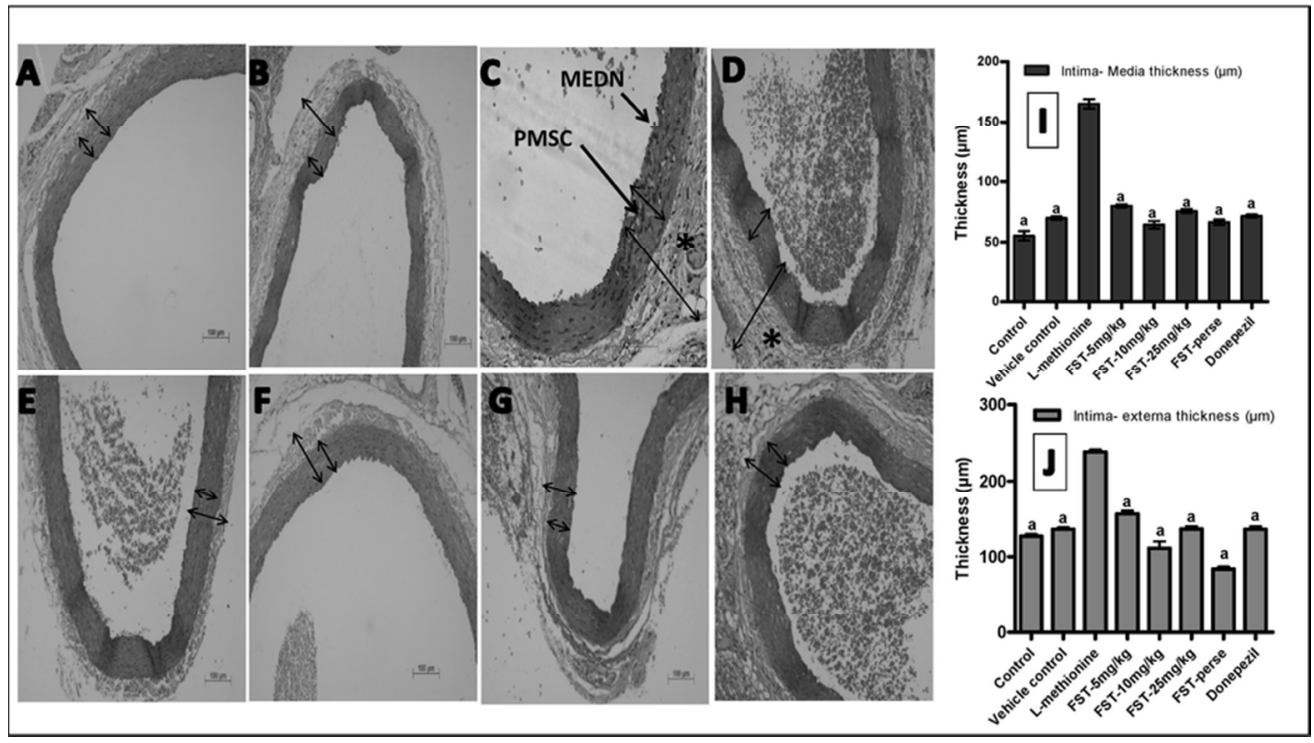

Fig. 4

$78 \times 44 \mathrm{~mm}(300 \times 300$ DPI $)$ 


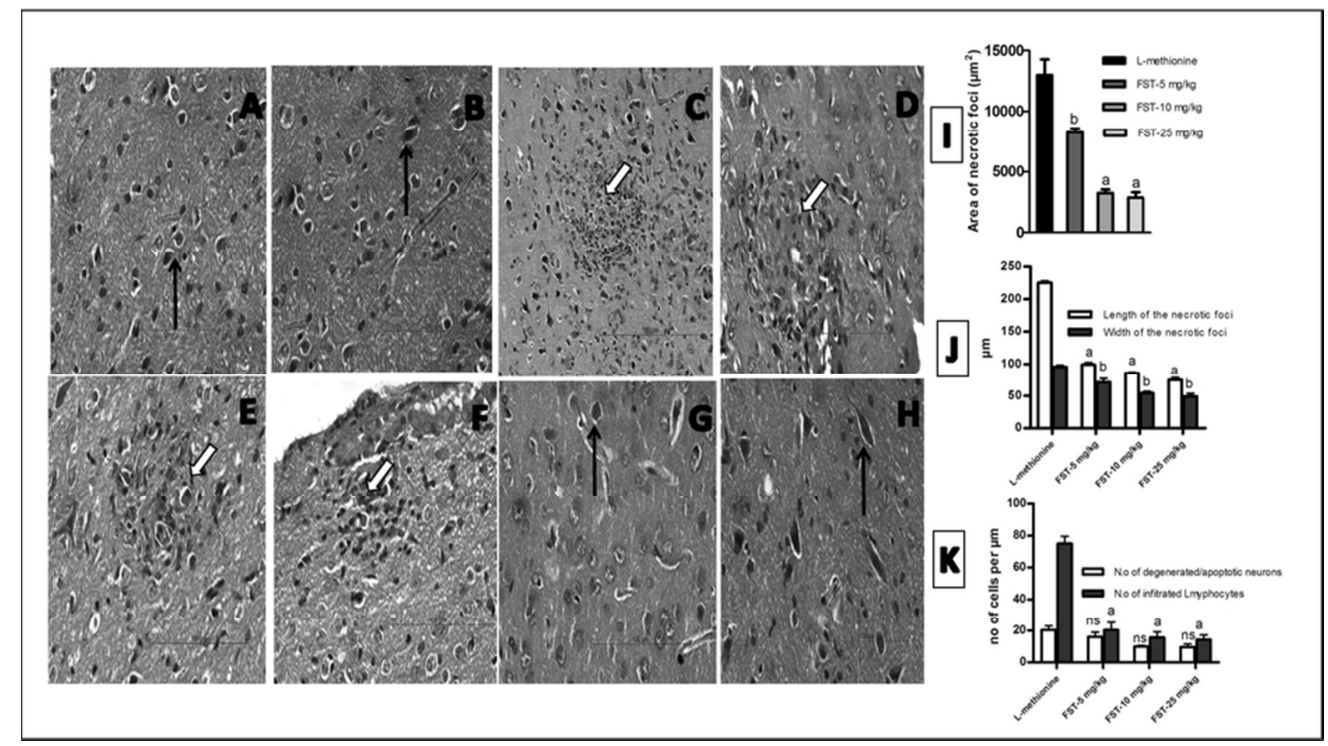

Fig. 5

$78 \times 44 \mathrm{~mm}(300 \times 300$ DPI $)$ 


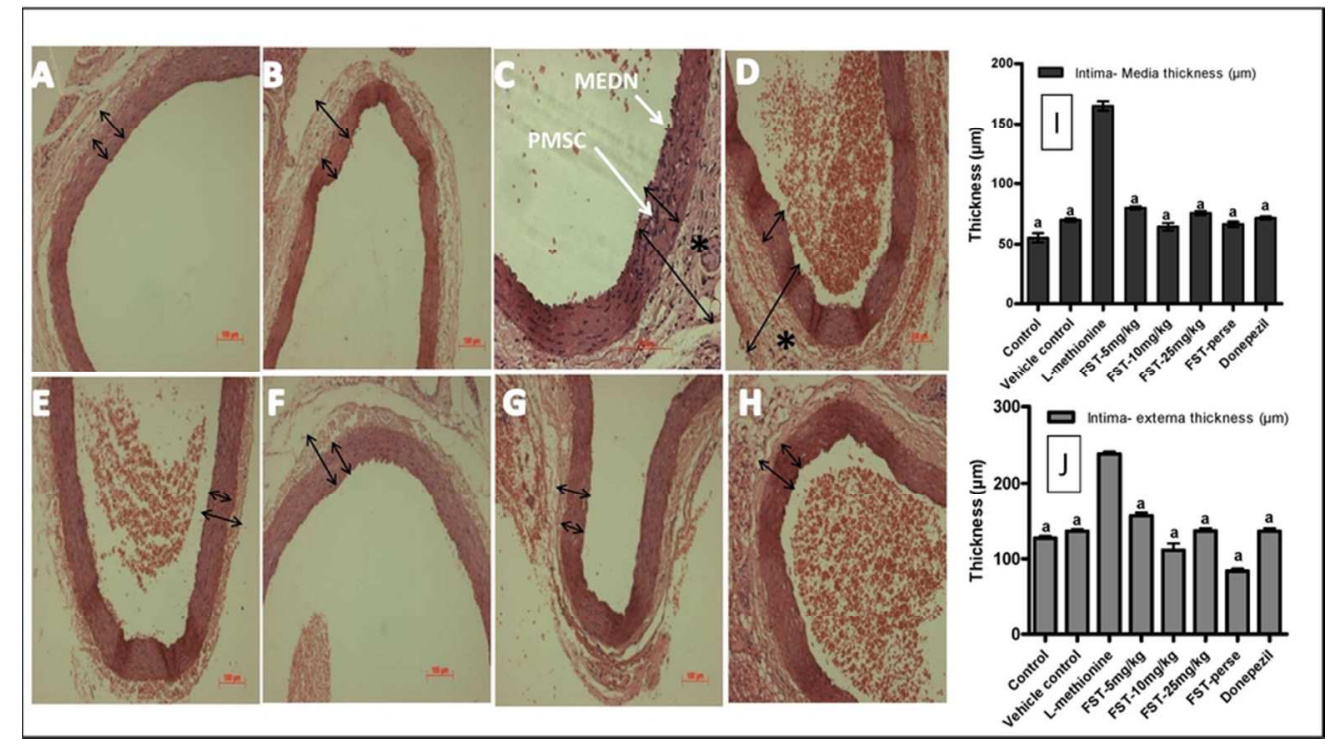

$78 \times 44 \mathrm{~mm}(300 \times 300$ DPI $)$ 


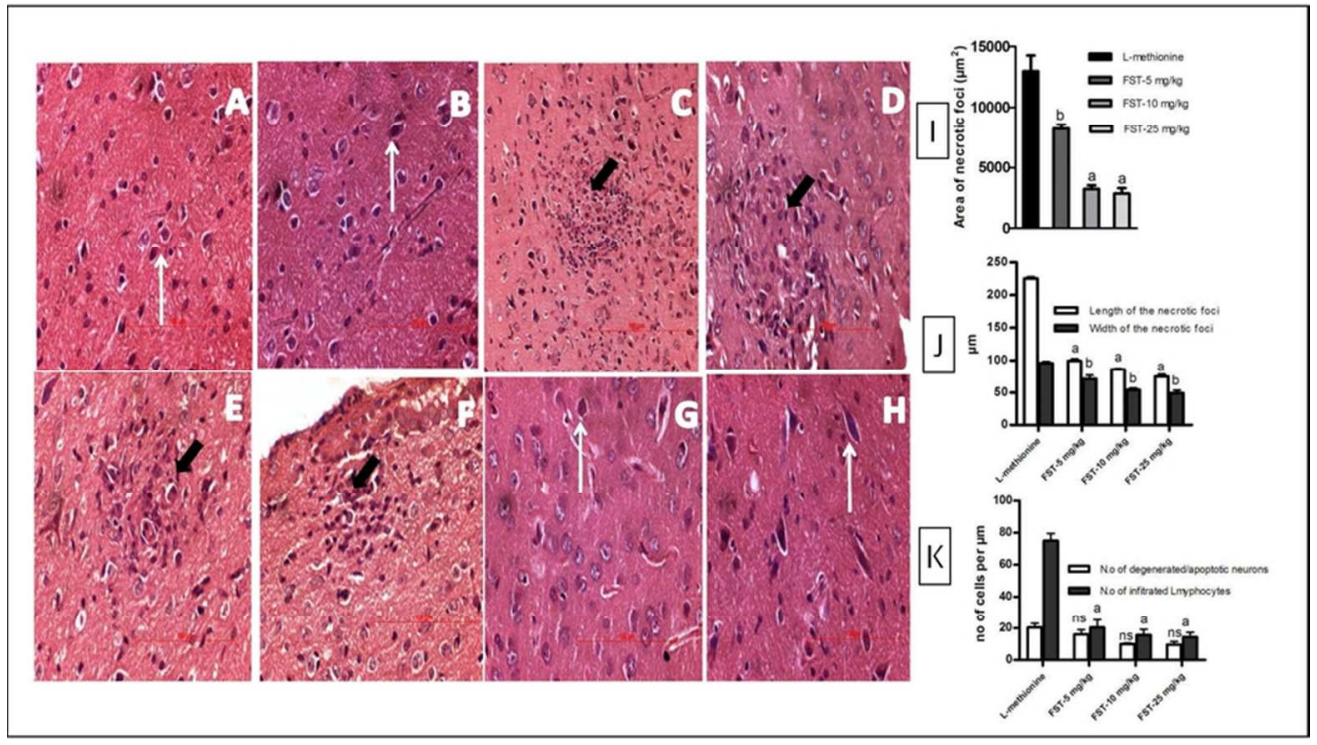

$79 \times 44 \mathrm{~mm}(300 \times 300$ DPI $)$ 